\title{
Narcolepsy: the impact of aging, hypocretin deficiency, and years of formal education in olfactory function and abdominal obesity
}

\author{
Narcolepsia: o impacto da idade, deficiência de hipocretina e anos de estudo na função \\ olfatória e na obesidade central
}

Giselle de Martin TRUZZI', Maria Fernanda NAUFEL' , Sergio TUFIK' , Fernando Morgadinho COELHO',2

\begin{abstract}
Background: Narcolepsy is a disease resulting from the loss of hypocretin-producing cells or other dysfunctions of the hypocretinergic system. In addition to sleep disorders, affected patients may experience increased weight gain, olfactory changes, and poorer quality of life. Methods: This study aimed to investigate the relationship between narcolepsy and weight gain, years of study, sleep parameters, and olfactory dysfunction in patients with narcolepsy type 1 and narcolepsy type 2. Anthropometric, olfactory, socioeducational, and excessive daytime sleepiness evaluations were performed in 77 patients. Results: Greater weight gain and abdominal obesity were observed in patients with type 1 narcolepsy. Patients with higher education level had lower scores of daytime sleepiness, higher scores on the olfactory function test, and lower rates of abdominal obesity. Discussion: Patients with narcolepsy type 1 showed an increased body weight and abdominal obesity when compared to narcolepsy type 2. The patients with a higher schooling level showed a reduction of the daytime sleepiness scores, lower rates of abdominal obesity, and better scores on the olfactory function test. Conclusion: Among all the patients with narcolepsy, the data indicated that aging and hypocretin deficiency are associated with abdominal obesity, while years of study is the variable that mostly influences olfaction function.
\end{abstract}

Keywords: Disorders of Excessive Somnolence; Hyposmia; Central Obesity; Education; Orexin.

\section{RESUMO}

Antecedentes: A narcolepsia é resultante da perda de células produtoras de hipocretina ou da disfunção do sistema hipocretinérgico. Além dos distúrbios do sono característicos da doença, os pacientes afetados podem apresentar também aumento de peso, alterações olfatórias e pior qualidade de vida. Métodos: 0 objetivo do estudo é investigar a relação entre a narcolepsia e o ganho de peso, anos de estudo, parâmetros do sono e a disfunção olfatória em pacientes com narcolepsia tipo 1 e narcolepsia tipo 2. Foram realizadas avaliações antropométricas, do olfato, sociais, educacionais e da sonolência excessiva diurna nos 77 indivíduos participantes da pesquisa. Resultados: Foram observados, nos pacientes com narcolepsia tipo 1, maior ganho de peso e maior frequência de obesidade central. Pacientes com ensino superior apresentaram escores mais baixos de sonolência excessiva diurna, escores mais altos no teste de função olfatória e menores taxas de obesidade central. Discussão: Pacientes com narcolepsia tipo 1 apresentaram maior ganho de peso e obesidade central quando comparados aos com narcolepsia tipo 2. Os pacientes com maior escolaridade apresentaram menores escores de sonolência diurna, de obesidade central e melhores escores no teste da função olfatória. Conclusão: Nos indivíduos com narcolepsia tipo 1 e tipo 2 , os dados indicaram que o envelhecimento e a deficiência de hipocretina estão associados à obesidade central, enquanto anos de estudo é a variável que mais influencia na função olfatória.

Palavras-chave: Distúrbios do Sono por Sonolência Excessiva; Hiposmia; Obesidade Central; Educação; Orexina.

\section{INTRODUCTION}

Narcolepsy is an autoimmune disease that causes excessive daytime sleepiness (EDS). The affected individuals may also present cataplexy, hypnagogic and/or hypnopompic hallucinations, sleep fragmentation, and sleep paralysis. The first symptoms usually occur in adolescents and young adults, and the diagnosis is made, on average, 10.5 years after the onset of symptoms ${ }^{1}$. In addition to the clinical manifestations of narcolepsy, electrophysiological tests (full-night

\footnotetext{
'Universidade Federal de São Paulo, Departamento de Psicobiologia, São Paulo SP, Brazil.

${ }^{2}$ Universidade Federal de São Paulo, Departamento de Neurologia e Neurocirurgia, São Paulo SP, Brazil.

GMT (iD https://orcid.org/0000-0002-2051-8259; MFN (iD https://orcid.org/0000-0001-8773-811X;

ST (D) http://orcid.org/0000-0002-3804-8865; FMC (D) https://orcid.org/0000-0002-8482-3754

Correspondence: Giselle de Martin Truzzi; Email: giselledmt@gmail.com.

Conflict of interest: There is no conflict of interest to declare.
}

Authors' contributions: GMT, MFN, ST, FMC: research idea and study design; GMT, MFN, FMC: data acquisition; GMT, MFN, FMC: data analysis/interpretation; GMT, MFN, FMC: statistical analysis; GMT, MFN, ST, FMC: manuscript drafting or revision.

Received on August 18, 2020; Received in its final form on October 09, 2020; Accepted on November 16, 2020.

\section{(cc) BY}


polysomnography followed by the Multiple Sleep Latency Test (MSLT)) are necessary to confirm the sleep disorder. For the diagnosis of narcolepsy, the results needed are a mean sleep latency of up to 8 minutes and two or more sleep onset REM periods (SOREMPS) in the MSLT. In patients with clinical manifestations, in addition to electrophysiological tests, hypocretin levels (Hcrt-1) can be measured in cerebrospinal fluid (CSF). If the CSF has a Hcrt-1 concentration of less than $110 \mathrm{pg} / \mathrm{mL}$ or less than $1 / 3$ of the average levels obtained in individuals without narcolepsy, the individual may be diagnosed with type 1 narcolepsy (NT1) 2 .

Although the loss of hypocretinergic cells is more pronounced in NT1, it can also occur in type 2 narcolepsy (NT2), but the levels still do not drop to levels below nor$\mathrm{mal}^{3}$. In humans, lower levels of Hcrt-1 were associated with narcolepsy, increased sleepiness, higher frequency of HLADQB1*0602, shorter sleep latency, and REM sleep latency ${ }^{4}$. Genetic predisposition seems to play a role in narcolepsy pathogenesis ${ }^{5,6}$.

The changes in the hypocretin system affect the sleep/ wake state and contribute to worsening sleep quality and quality of life. The disease is associated with stigmatization in work and study environments, higher occurrence of comorbidities, and a greater number of psychiatric disorders ${ }^{7}$. Patients with narcolepsy may also have some degree of olfactory dysfunction ${ }^{8-10}$. Although hypocretin cells are located in the lateral hypothalamus, hypocretin and its fibers can be detected in the olfactory pathway, suggesting that hypocretin may play a role in modulating the olfactory message ${ }^{11}$. There is also an increase in overweight and obesity rates in individuals with narcolepsy, showing that dysfunction in the hypocretinergic system could have effects on the individual's energy balance ${ }^{12}$.

This study aimed to investigate the relationship between narcolepsy and patients' sociodemographic conditions, such as years of schooling and age. We also evaluated olfactory dysfunction and body composition of individuals through anthropometric and bioimpedance measurements in order to assess total and abdominal obesity, and EDS and olfaction in patients with NT1 and NT2.

\section{METHODS}

\section{Study design and population}

A cross-sectional study was conducted with patients diagnosed with narcolepsy. Ethical approval was granted by the Ethics Committee of the Universidade Federal de São Paulo (UNIFESP) (CEP: \#1348/2017), and all participants signed the informed consent.

Seventy-seven patients with narcolepsy from the outpatient clinic of Excessive Daytime Sleepiness of Departamento de Psicobiologia of UNIFESP were included. The study data were collected between the years 2017 and 2019. Fifty-six of participants were diagnosed with NT1 and 21 with NT2, and all of them were aged 18 years or older. The diagnosis was performed according to the American Academy of Sleep Medicine (ICSD-3) criteria and all the participants were under continuous and monitored treatment.

Besides the application of the Epworth Sleepiness Scale, the diagnosis of narcolepsy was confirmed in all participants by a full-night polysomnography followed by a MSLT. Moreover, all patients were investigated for the presence of allele HLA-DQB1*0602 and CSF levels of Hcrt-1 by radioimmunoassay test kits.

Sociodemographic data (age, gender, years of study) and clinical parameters such as EDS, olfactory dysfunction, body mass index, waist-to-hip ratio, and waist-to-height ratio were assessed to evaluate factors that might predict the comorbidities of olfactory dysfunction and abdominal obesity. Exercise habits and the use of medications were also noted. For the study, we considered the use of antidepressants, stimulants, and L-carnitine. Stimulant drugs (such as Modafinil and Methylphenidate) are widely used medications in patients with narcolepsy to control EDS and a few antidepressants are used to control cataplexy and hallucinations ${ }^{13}$. It is important to note that we did not specify which patients used antidepressants due to narcolepsy symptoms or for depression only. L-carnitine has been shown to improve narcolepsy symptoms and was prescribed for part of our patients with contraindications to stimulants use ${ }^{14}$.

\section{Daytime sleepiness assessment by Epworth sleepiness scale}

Daytime sleepiness was measured by the Epworth Sleepiness Scale (ESS). The ESS consists of a self-administered questionnaire with 8 questions, where patients are asked to rate their usual chances to fall asleep or dozing off in everyday situations. The total score can range from 0 to 24 , and higher scores indicated increased daytime sleepiness. A score above 10 indicates the possibility of daytime sleepiness. A Portuguese-language version of the ESS, which was validated for use in Brazil, was applied in our patients ${ }^{15}$.

\section{Anthropometric assessments}

A trained dietitian performed all the measurements that included body mass $(\mathrm{kg})$, height $(\mathrm{cm})$, body mass index (BMI), waist circumference $(\mathrm{cm})$, hip circumference $(\mathrm{cm})$, waist-to-hip ratio (WHR), and waist-to-height ratio (WHtR). Our objective was to investigate the incidence of total and abdominal obesity.

BMI was calculated by the formula weight $(\mathrm{kg}) / \mathrm{heigh}^{2}\left(\mathrm{~m}^{2}\right)$ and classified according to the World Health Organization parameters: underweight $\left(<18.5 \mathrm{~kg} / \mathrm{m}^{2}\right)$, eutrophic (18.5-24.9 $\left.\mathrm{kg} / \mathrm{m}^{2}\right)$, overweight $\left(25.0-29.0 \mathrm{~kg} / \mathrm{m}^{2}\right)$, and obese $(\geq 30.0 \mathrm{~kg} /$ 
$\mathrm{m}^{2}$ ). Overweight and obesity increases the risk of coronary heart disease, ischemic stroke, and type 2 diabetes mellitus ${ }^{16}$.

Besides, WHR above the cut off values ( $>0.85$ for females and $>0.90$ for males for WHR) and WHtR above $>0.50$ for both males and females indicates abdominal obesity, which is associated with a higher incidence of coronary heart disease and type 2 diabetes ${ }^{17,18}$.

\section{Olfactory assessment}

The University of Pennsylvania Smell Identification Test (UPSIT) was used to evaluate olfaction. The version of the UPSIT that was used in our study was standardized for the Portuguese language and adapted for the Brazilian culture. The 40-item UPSIT is a multiple-choice test used to measure the ability for odor identification. UPSIT consists of 4 booklets with 10 pages each, containing different "scratch and sniff" odorant strips. To identify the odor of each page, the patient chooses 1 out of 4 possible answers. Higher test scores indicate better olfactory function. The scores range from 0 to 40, and the total score allows the classification of the olfaction acuity as "anosmia", "severe microsmia", "moderate microsmia”, "mild microsmia" and "normosmia".

The routine ear, nose, and throat examination was performed in all participants before the UPSIT, to confirm that they had no problem that could invalidate the test ${ }^{19}$.

\section{Exclusion criteria}

Exclusion criteria included disagreement in participating, possible pre-existing hyposmia due to causes such as nasal surgeries, nasal diseases, active infections, a history of tumors, traumatic brain injury, epilepsy, multiple sclerosis, Parkinson's disease, Alzheimer's disease, Lewi Body Dementia, and other memory disorders. Patients with pacemakers and women who were pregnant were also excluded.

\section{Statistical analysis}

Statistical analysis was performed using SPSS ver. 18.0 (IBM, Armonk, NY, USA). The Shapiro-Wilk test was used to check normality. The Student's t test was applied for the comparison of the parametric variables, which are presented as mean-standard error. The Mann-Whitney U test was used to compare differences between nonparametric variables, and these data are presented as medians (minimum-maximum). Categorical variables are showed as percentage and were compared by the Chi-square test. The Pearson's correlation coefficient was used to compare the correlation between subjective sleep (assessed by the ESS), anthropometric, and clinical parameters. The variables that showed significant correlations in the Pearson's univariate analyses were tested in multivariate linear regression analyses, to evaluate significant predictors for waist-to-hip ratio and UPSIT score. All the patients were included in both the univariate and multivariate analyses. Sample size was calculated for a statistical power of 0.85, an effect size of 0.19, an alpha level of 0.05, and 3 predictors. A total of 69 volunteers with narcolepsy was the required sample size. Statistical significance was set at a level of $\mathrm{p}<0.05$.

\section{RESULTS}

Compared to patients diagnosed with NT2, the NT1 group had higher mean age $(\mathrm{P}=0.0434)$ and lower sleep latency $(\mathrm{P}=0.0114)$, Hcrt-1 levels $(\mathrm{P}<0.00001)$ and exercise habits $(\mathrm{P}=0.0496)$, whereas UPSIT scores, BMI, WHR, WHtR, positive HLA allele prevalence, and use of antidepressant were higher (Table 1).

Table 2 shows that ESS was negatively correlated with years of study, while years of study was also negatively correlated with age $(\mathrm{P}<0.001)$ and WHR but positively correlated with UPSIT scores $(\mathrm{P}<0.001)$ and height $(\mathrm{P}=0.025)$. The age of the patients was negatively correlated with years of study $(\mathrm{P}<0.001)$ and positively with WHR $(\mathrm{P}<0.001)$.

As shown in Table 2, UPSIT score was positively correlated with years of study $(\mathrm{P}<0.001)$. Significant negative correlations were found between WHR and Hcrt-1 levels ( $\mathrm{P}=0.004)$, and years of study, while a negative correlation was found between WHR and age $(\mathrm{P}<0.001)$.

The linear regression model that had WHR as the dependent variable, is shown in Table 3. The independent variable years of study $(\mathrm{P}=0.11)$ was removed as it showed non-significant influence. The final model explained $33 \%$ of WHR variations ( 3 predictors, $\mathrm{R}=0.57, \mathrm{R}^{2}=0.33$, adjusted $\mathrm{R}^{2}=0.30$, $\mathrm{F}_{2,50}=12.34$, statistical power $\left.=0.99, \mathrm{P}<0.0001\right)$ and showed that age $(\mathrm{P}=0.0031)$ and Hcrt-1 levels $(\mathrm{P}=0.025)$ were positively associated with WHR.

From linear regression model for UPSIT scores as the dependent variable (Table 4$)$, the variable height $(\mathrm{P}=0.32)$ was removed after the analysis showed non-significant influence. The final model explained $16 \%$ of UPSIT variations (2 predictors, $\mathrm{R}=0.39, \mathrm{R}^{2}=0.16$, adjusted $\mathrm{R}^{2}=0.14, \mathrm{~F}_{1,72}=13.30$, statistical power $=0.79, \mathrm{P}<0.0005)$, showing that years of study $(\mathrm{P}=0.0005)$ was positively associated with UPSIT scores. The regression models explained only partially the variations in WHR and UPSIT scores.

\section{DISCUSSION}

We found that patients with NT1 had a significantly higher BMI compared with patients with NT2; moreover, the median BMI value of NT1 was higher than the cut off point for obesity, while the BMI of the NT2 group was within the cut off points. Furthermore, the WHR was greater in NT1 individuals compared to the NT2 group, and the WHR of the NT1 group was also higher than the cut off points, showing that these patients have a higher prevalence of abdominal obesity. 
Table 1. Clinical, anthropometric and sociodemographic characteristics, diagnostic test, lifestyle habits, and use of medications of patients with NT1 e NT2.

\begin{tabular}{|c|c|c|c|}
\hline & $\begin{array}{l}\text { Narcolepsy type } 1 \text {, } \\
n=56\end{array}$ & $\begin{array}{c}\text { Narcolepsy type 2, } \\
n=21\end{array}$ & $P$ \\
\hline Age (years) b & $38.5(32-47.5)$ & $30.0(26-42)$ & 0.0434 \\
\hline Years of formal education ${ }^{a}$ & $13.4 \pm 0.7$ & $15.0 \pm 0.6$ & 0.1588 \\
\hline Gender $(\text { male })^{c}$ & 41.1 & 27.3 & 0.2565 \\
\hline UPSIT(score) ${ }^{b}$ & $31.7(10-39)$ & $34.0(16-39)$ & 0.7101 \\
\hline Sleep latency ${ }^{a^{\star}}$ & $2.7 \pm 0.4$ & $4.89 \pm 0.76$ & 0.0114 \\
\hline SOREMPSa & $3.35 \pm 1.43$ & $2.40 \pm 1.0$ & 0.0095 \\
\hline HLA-DQB1*0602 (positive) ${ }^{c}$ & 73.6 & 47.6 & 0.0332 \\
\hline Epworth sleepiness scale & $19(1-24)$ & $13(4-23)$ & 0.0010 \\
\hline Hypocretin-1 (pg/mL) $)^{b}$ & $27.7(0-142)$ & $349.3(139-435)$ & $<0.0000$ \\
\hline Body mass index $\left(\mathrm{kg} / \mathrm{m}^{2}\right)^{\mathrm{b}}$ & $31.3(20.6-45,5)^{*}$ & $23.3(15.5-38.1)^{*}$ & $<0.0001$ \\
\hline Waist-to-Hip Ratio ${ }^{a}$ & $0.89 \pm 0.01$ & $0.80 \pm 0.02$ & 0.0028 \\
\hline Waist-to-Height Ratiob & $0.66(0.55-0.89)$ & $0.61(0.49-0.76)$ & 0.0014 \\
\hline Regular exercise ${ }^{c}$ & 28.0 & 52.4 & 0.0496 \\
\hline Antidepressant users ${ }^{c}$ & 73.6 & 47.6 & 0.0332 \\
\hline Stimulant users ${ }^{\circ}$ & 66.0 & 52.4 & 0.2748 \\
\hline L-Carnitin users ${ }^{c}$ & 9.3 & 9.5 & 0.9905 \\
\hline
\end{tabular}

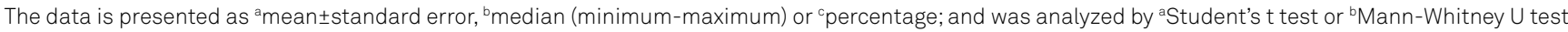
or ${ }^{\circ}$ Chi-Square test. Bold values indicate statistical significance. Years was described as median (lower and upper quartile). Sleep latency and SOREMPs (Sleep Onset REM Periods) were assessed by the Multiple Sleep Latency Test. *BMI classification: NT1 - Obesity; NT2 - Eutrophy. WHR classification: Adequate for men with NT1 and NT2 and increased for women with NT1. WHtR (Waist-to-Height Ratio) classification: increased for both NT1 and NT2.

Table 2. Pearson correlation coefficients between sleep, anthropometric, and clinical parameters.

\begin{tabular}{|c|c|c|c|c|c|c|c|c|}
\hline & \multicolumn{2}{|c|}{ ESS } & \multicolumn{2}{|c|}{ YS } & \multicolumn{2}{|c|}{ UPSIT } & \multicolumn{2}{|c|}{ WHR } \\
\hline & $\begin{array}{l}\text { Pearson } \\
\text { correlation }\end{array}$ & $\begin{array}{c}P \\
\text { (2-tailed) }\end{array}$ & $\begin{array}{l}\text { Pearson } \\
\text { correlation }\end{array}$ & $\begin{array}{c}P \\
\text { (2-tailed) }\end{array}$ & $\begin{array}{l}\text { Pearson } \\
\text { correlation }\end{array}$ & $\begin{array}{c}P \\
\text { (2-tailed) }\end{array}$ & $\begin{array}{l}\text { Pearson } \\
\text { correlation }\end{array}$ & $\begin{array}{c}P \\
\text { (2-tailed) }\end{array}$ \\
\hline Hypocretin & 0.1920 & 0.182 & 0.1923 & 0.182 & 0.1001 & 0.447 & -0.4320 & 0.004 \\
\hline ESS & - & - & -0.3360 & 0.008 & -0.0616 & 0.634 & 0.1969 & 0.125 \\
\hline Age & 0.1985 & 0.122 & -0.4340 & 0.000 & -0.0098 & 0.940 & 0.4376 & 0.000 \\
\hline UPSIT & -0.0616 & 0.634 & 0.4695 & 0.000 & - & - & -0.1693 & 0.181 \\
\hline WHR & 0.2023 & 0.109 & -0.3731 & 0.002 & -0.1639 & 0.203 & - & - \\
\hline WHtR & 0.1589 & 0.210 & -0.0844 & 0.507 & -0.1604 & 0.206 & 0.2298 & 0.068 \\
\hline Height & -0.0284 & 0.763 & 0.2799 & 0.025 & 0.2297 & 0.072 & 0.1595 & 0.208 \\
\hline
\end{tabular}

YS:Years of formal education; ESS: Epworth Sleepiness Scale; WHR: Waist-to-Hip Ratio; WHtR: Waist-to-Height Ratio. *p $<0.05$.

Table 3. Linear regression model for predictors of WHR among 77 patients with narcolepsy.

\begin{tabular}{lccc}
\hline \multicolumn{4}{c}{ Dependent variable: WHR } \\
\hline Predictors & Beta coefficients & Standard error & $P$ \\
Age & 0.0032 & 0.001 & 0.0031 \\
Hypocretin & -0.0002 & 0.000 & 0.0025 \\
Intercept & 0.7881 & 0.043 & 0.0000 \\
\hline
\end{tabular}

WHR: Waist-to-Hip Ratio; $R=0.57 ; R^{2}=0.33$; adjusted $R^{2}=0.30 ; F_{2,50}=12.34 ; P<0.00004$. The model was adjusted for Years of $S t u d y(P=0.11)$.

Table 4. Linear regression model for predictors of UPSIT among 77 patients with narcolepsy.

\begin{tabular}{|c|c|c|c|}
\hline \multicolumn{4}{|c|}{ Dependent variable: UPSIT } \\
\hline Predictors & Beta coefficients & Standard error & $P$ \\
\hline Years of Formal Education & 0.473 & 0.130 & 0.0005 \\
\hline Intercept & 25.412 & 1.892 & 0.0000 \\
\hline
\end{tabular}

$R=0.39 ; R^{2}=0.16$; adjusted $R^{2}=0.14 ; F_{1,2}=13.30 ; P<0.0005$ The model was adjusted for Height $(P=0.32)$. 
These data are in agreement with previous studies showing increased fat mass and abdominal obesity in patients with hypocretin deficiency, when comparing to both healthy population and patients diagnosed with $\mathrm{NT} 2^{20}$. WHtR was above the cut off values for both groups, which indicates a higher volume of visceral fat even in patients with NT2. It has previously been established that there is a tendency towards central obesity in all patients with narcolepsy ${ }^{21}$.

WHR and WHtR are anthropometric measures that can be used to predict abdominal adiposity ${ }^{22}$. Other measures such as sagittal abdominal diameter and imaging tests can also be used. Several studies show that adiposity may be related to individuals' sociodemographic factors. In a Brazilian study it was observed that increased income was associated with greater waist and hip measurements in men. In women, lower income was associated with higher WHR ${ }^{23}$.

The negative association between WHR and Hcrt-1 levels, found in the linear regression model, confirms that Hcrt-1 deficiency leads to an increased proportion of abdominal fat, corroborating with a decreased health-related quality of life and increased mortality rate in patients with NT1. Although we included all patients with narcolepsy in the regression analysis, the results demonstrates that patients with NT1 have greater abdominal obesity when compared to NT2 patients, and patients with NT1 have lower CSF levels of Hcrt-1.

Indeed, patients with NT1 have also a higher incidence of dyslipidemia, hypertension, glucose intolerance, diabetes, obstructive sleep apnea, metabolic syndrome, and endocrinopathies ${ }^{24,25}$. Children with narcolepsy have a higher prevalence of obesity and exhibit a reduced basal metabolic rate when compared to individuals not affected by the disease ${ }^{26}$. In addition, puberty was observed at a younger age in patients with narcolepsy, even when compared to obese individuals without narcolepsy. It was also observed that the earlier onset of narcolepsy was associated with early puberty ${ }^{27}$.

Hypocretin is linked to the pathogenesis of narcolepsy and its deficiency is probably related to weight gain. In humans, hypocretin is produced by approximately 50,000 to 80,000 neurons in the lateral hypothalamus ${ }^{28}$. Hypocretin receptors are expressed in several areas of the central nervous system, and also in peripheral organs and tissues like ovaries, adrenal glands, thyroid, testis, kidney, jejunum, lung, adrenal, and pituitary gland. The wide distribution and interaction of hypocretin receptors with different systems and modulators suggest their involvement in different functions. Among them is sleep/wake regulation, thermoregulation, eating behavior, cardiovascular responses, among others. Hypocretin still plays an important role in motivation, reward-seeking behavior, and possible changes in eating behavior.

The relationship between Hcrt-1 and obesity in humans is complex. Models show that factors such as sleep/wakefulness status, quality of sleep, physical activity levels, and food intake can be affected by changes in the hypocretinergic system, causing weight gain in the affected group to be multifactorial ${ }^{12}$. In our study, we found that patients with Hcrt-1 deficiency (NT1) are less likely to exercise (only $28 \%$ of individuals with NT1 exercise regularly) corroborating with this hypothesis.

Patients with narcolepsy can also have higher frequency of binge eating and a greater desire to consume food. These individuals have also higher rates of eating disorders, such as anorexia or bulimia nervosa, when compared to healthy controls. In a particular study, when patients with NT1 were exposed to unrestricted access to snacks, they consumed more calories than the control group, which could be an indication of lower satiety in the affected group ${ }^{29}$. Thus, patients with NT1 are more frequently affected by eating disorders and greater weight gain, which must be monitored and treated to avoid complications and comorbidities.

Antidepressants, Methylphenidate, Modafinil, and Lysdexamphetamine were used to treat our narcolepsy patients. It is known that Sodium Oxybate, a medication with a potent anticatapletic effect, decreases BMI in patients with narcolepsy ${ }^{12}$. However, as the medication is not yet approved in Brazil, this benefit is not possible for our sample. Despite not widely used by individuals included in the study, some antidepressants could lead to weight gain, worsening the condition of patients with narcolepsy. ${ }^{30}$

Regarding years of study, there was no significant difference between individuals with NT1 and NT2 (12\% of the patients completed elementary school, $31 \%$ completed high school, 30\% completed higher education, and 14\% completed graduate school). The average years of study were 14.01 for women and 13.55 for men. The educational level of the affected group was above the national average of 9.96 years, but close to the values of the state of São Paulo (13.23 years), where the research was carried out. The age of the patients correlates negatively with the years of formal education. A possible explanation for the finding is that the access of formal education has increased in recent years in Brazil ${ }^{31}$.

In previous studies, no differences were found in years of formal education between patients diagnosed with narcolepsy and healthy controls, even though individuals with narcolepsy reported more difficulties with attention and concentration. They may show worse performances in activities with cognitive demand, but the alteration is related to the sleepiness presented by these individuals and not to a cognitive dysfunction. Individuals who were correctly diagnosed with narcolepsy soon after the onset of symptoms had lower rates of unemployment and inactivity and a higher level of education than those whose diagnosis took longer. People with narcolepsy also have lower employment rates when compared to controls ${ }^{32}$.

Most previous studies that compared people with and without narcolepsy regarding years of formal education found no differences between the groups. Nevertheless, literature is poor in studies comparing the years of study between 
NT1 and NT2. Our results showed that patients with NT1 had higher EDS due to higher severity of the disease. Although NT1 patients could face more difficulties in formal education due to the EDS, there was no difference between the two groups $^{33}$.

The present study found a negative correlation between WHR and educational levels, similar to what is described in the literature for individuals without narcolepsy. In children with narcolepsy, obesity was associated with school absenteeism ${ }^{34}$. Data on the association between obesity and years of study in patients with narcolepsy are scarce in the literature. To the best of our knowledge, our study is the first to investigate the association between abdominal obesity and years of study in patients with narcolepsy.

Studies have shown, in individuals without narcolepsy, an inverse correlation between education levels and obesity, though some found this correlation to be present in women but not men. In women there is an inverse association between years of study and abdominal obesity. It was observed that women with higher education gained less weight over the years. Obesity during childhood, however, can be a factor that influences schooling and was associated with fewer years of study in early adulthood ${ }^{35}$.

The mean levels of hyposmia were mild in both groups, and a direct correlation between the number of correct answers at UPSIT and the level of formal education was found. Moreover, the linear regression model implied that for every one-unit of Years of Study the UPSIT score increases by 0.5. Studies have shown that less years of education was correlated to a decrease in UPSIT scores in adults and in the elderly. Individuals evaluated by the Sniffin' Sticks, another olfactory test, had also worse scores when they had fewer years of study. Some of the hypotheses that might explain these differences are that people with fewer years of education could have been less exposed to various odors, or they could have a worse understanding of the proposed olfactory test $^{36}$.

Although we observed better UPSIT scores in patients with NT2 when compared to NT1, these data were not statistically significant.

Neurodegenerative diseases with autonomic disorders can be implicated in hyposmia ${ }^{37}$. There is also an increase in REM sleep behavior disorder and dysautonomy in questionnaire evaluations ${ }^{38}$. Dysautonomy correlates with systemic changes, having an effect not only on the olfactory function but also in body composition and in the increased risk of cardiometabolic diseases.

Thus, the loss of hypocretin cells could impact the olfactory system. There is an extensive distribution of the hypocretinergic system (in the cortex, olfactory bulb, basal ganglia, amygdala, locus coeruleus, raphe nuclei, parabrachial nuclei, substantia nigra, and reticular formation) ${ }^{39}$. Although we have also observed olfactory alterations in patients diagnosed with NT2, it is not possible to explain with the hypocretin deficiency theory. Thus, further studies with NT2 patients are needed to verify and explain its possible olfactory dysfunction.

The ESS is a subjective test that assesses the patient's level of sleepiness, and patients with narcolepsy achieve higher scores in comparison with healthy individuals. In this study, we observed that the mean ESS value was significantly higher in patients with NT1 when compared with those with NT2, while the sleep latency was lower in the NT1 group. Patients diagnosed with NT1 present marked changes in the hypocretinergic system, which lead to a severe form of the disease. Therefore, it is expected that these patients present a higher level of drowsiness and a decreased sleep latency when compared to patients with $\mathrm{NT} 2^{40}$. As expected, there were higher numbers of SOREMPS in patients with NT1.

Higher scores on the ESS are related to a greater number of SOREMPS in the MSLT. In patients with sleepiness, the ESS can be used in association with other tests for the assessment and evaluation of the degree of the daytime sleepiness. In these individuals, assessing the effectiveness of the purposed drug treatment may also help ${ }^{41}$. It is important to emphasize, however, that ESS should not be used as a single tool for the classification of excessive sleepiness, as it may be influenced by other factors, such as depression and anxiety ${ }^{42}$, and must be accompanied by other evaluation criteria ${ }^{43}$.

Our study showed an inverse correlation between years of study and the ESS score. There are few data in the literature on the relationship between those two variables. One study found ESS to be valid to assess excessive sleepiness in individuals with various sleep disorders, including narcolepsy, regardless of the patients' educational level ${ }^{44}$.

Considering the years of study and ESS scores, there is a possibility that the relationship was found due to an incorrect understanding of the test by patients with lower educational level. It is important to highlight, however, that the physician-administered ESS was used for all patients in the present research, following a previous explanation of the test, to facilitate the understanding. In another study, researchers found no differences between schooling and ESS score results when doctors applied the test. This difference, however, was observed when the test was self-administered ${ }^{45}$.

The age difference between the groups with NT1 and NT2 is a limitation of the study, as patients with NT1 were, on average, older than those with NT2. Since obesity tends to increase with age, this may be a factor that changes the results of the study. The age difference may influence the scores of ESS found in elderly patients ${ }^{46}$. However, considering the difference in the average age of 30 and 39 years in the two groups, this would not represent an important bias in the research.

In conclusion, the present findings showed an increase in body weight and abdominal obesity in patients with NT1, compared to NT2. Patients with narcolepsy with a higher schooling level showed lower daytime sleepiness scores, 
lower rates of abdominal obesity, and better scores on the olfaction function test. The data indicate that the aging process and the hypocretin deficiency are associated with abdominal obesity, while the years of study was the variable that mostly influenced olfaction function. Despite the already established correlation between narcolepsy and weight gain and excessive sleepiness, the authors believe it is important to evaluate the influence of education level and social factors on these aspects. Furthermore, it is important to monitoring weight gain and abdominal obesity when treating patients with narcolepsy. Further studies are necessary in order to better understand these findings.

\section{ACKNOWLEDGEMENTS}

Associação Fundo de Incentivo à Pesquisa (AFIP, financial support), Senne Líquor Diagnóstico, and Hospital Israelita Albert Einstein. Dr. Ling Lin and Dr. Emanuel Mignot from the Department of Psychiatric and Behavior Science at Stanford University (California, USA).

\section{REFERENCES}

1. Morrish E, King MA, Smith IE, Shneerson JM. Factors associated with a delay in the diagnosis of narcolepsy. Sleep Med. 2004 Jan;5(1):3741. https://doi.org/10.1016/j.sleep.2003.06.002

2. American Academy of Sleep Medicine. International classification of sleep disorders. 3rd ed. Darien (IL): AASM; 2014.

3. Blouin AM, Thannickal TC, Worley PF, Baraban JM, Reti IM, Siegel JM. Narp immunostaining of human hypocretin (orexin) neurons: loss in narcolepsy. Neurology. 2005 Oct 25;65(8):1189-92. https://doi. org/10.1212/01.wnl.0000175219.01544.c8

4. Andlauer O, Moore Ht, Hong S-C, Dauvilliers Y, Kanbayashi T, Nishino $\mathrm{S}$, et al. Predictors of hypocretin (orexin) deficiency in narcolepsy without cataplexy. Sleep. 2012 Sep 1;35(9):1247-55. https://doi. org/10.5665/sleep.2080

5. Peyron C, Faraco J, Rogers W, Ripley B, Overeem S, Charnay Y, et al. A mutation in a case of early onset narcolepsy and a generalized absence of hypocretin peptides in human narcoleptic brains. Nat Med. 2000 Sep;6(9):991-7. https://doi.org/10.1038/79690

6. Guilleminault C, Mignot E, Grumet FC. Familial patterns of narcolepsy. Lancet. 1989 Dec 9;2(8676):1376-9. https://doi.org/10.1016/S01406736(89)91977-6

7. Rocca FL, Finotti E, Pizza F, Ingravallo F, Gatta M, Bruni O, et al. Psychosocial profile and quality of life in children with type 1 narcolepsy: a case-control study. Sleep. 2016 Jul 1;39(7):1389-98. https://doi.org/10.5665/sleep.5970

8. Baier PC, Weinhold SL, Huth V, Gottwald B, Ferstl R, Hinze-Selch D. Olfactory dysfunction in patients with narcolepsy with cataplexy is restored by intranasal Orexin A (Hypocretin-1). Brain. 2008 Oct;131(10):2734-41. https://doi.org/10.1093/brain/awn193

9. Bayard S, Plazzi G, Poli F, Serra L, Ferri R, Dauvilliers Y. Olfactory dysfunction in narcolepsy with cataplexy. Sleep Med. 2010 Oct;11(9):876-81. https://doi.org/10.1016/j.sleep.2010.07.004

10. Buskova J, Klaschka J, Sonka K, Nevsimalova S. Olfactory dysfunction in narcolepsy with and without cataplexy. Sleep Med. 2010 Jun;11(6):558-61. https://doi.org/10.1016/j.sleep.2010.01.009

11. Gorojankina T, Grébert D, Salesse R, Tanfin Z, Caillol M. Study of orexins signal transduction pathways in rat olfactory mucosa and in olfactory sensory neurons-derived cell line Odora: multiple orexin signalling pathways. Regul Pept. 2007 Jun 7;141(1-3):73-85. https:// doi.org/10.1016/j.regpep.2006.12.012

12. Nixon JP, Mavanji V, Butterick TA, Billington CJ, Kotz CM, Teske JA. Sleep disorders, obesity, and aging: the role of orexin. Ageing Res Rev. 2015 Mar;20:63-73. https://doi.org/10.1016/j.arr.2014.11.001

13. Bassetti CLA, Adamantidis A, Burdakov D, Han F, Gay S, Kallweit U, et al. Narcolepsy - clinical spectrum, aetiopathophysiology, diagnosis and treatment. Nat Rev Neurol. 2019 Sep;15(9):519-39. https://doi. org/10.1038/s41582-019-0226-9
14. Miyagawa T, Kawamura H, Obuchi M, Ikesaki A, Ozaki A, Tokunaga K, et al. Effects of oral L-carnitine administration in narcolepsy patients: a randomized, double-blind, cross-over and placebo-controlled trial. PLoS One. 2013;8(1):e53707. https://doi.org/10.1371/journal. pone. 0053707

15. Bertolazi AN, Fagondes SC, Hoff LS, Pedro VD, Barreto SSM, Johns MW. Portuguese-language version of the Epworth sleepiness scale: validation for use in Brazil. J Bras Pneumol. 2009 Sep;35(9):877-83. https://doi.org/10.1590/S1806-37132009000900009

16. World Health Organization. Public Health Nutrition. Geneva: WHO; 2004.

17. World Health Organization. Waist circumference and waist-hip ratio: report of WHO expert consultation. Geneva:WHO; 2008.

18. Emdin CA, Khera AV, Natarajan P, Klarin D, Zekavat SM, Hsiao AJ, et al. Genetic association of waist-to-Hip Ratio with Cardiometabolic Traits, type 2 diabetes, and coronary heart disease. JAMA. 2017 Feb 14;317(6):626-34. https://doi.org/10.1001/jama.2016.21042

19. Fornazieri MA, Doty RL, Santos CA, Pinna F de R, Bezerra TFP, Voegels RL. A new cultural adaptation of the University of Pennsylvania Smell Identification Test. Clinics (São Paulo). 2013 Jan;68(1):65-8. https:// doi.org/10.6061/clinics/2013(01)OA10

20. Sonka K, Kemlink D, Busková J, Pretl M, Srůtková Z, Horvat EM, et al. Obesity accompanies narcolepsy with cataplexy but not narcolepsy without cataplexy. Neuro Endocrinol Lett. 2010;31(5):631-4.

21. Drissi NM, Romu T, Landtblom A-M, Szakács A, Hallböök T, Darin N, et al. Unexpected fat distribution in adolescents with Narcolepsy. Front Endocrinol (Lausanne). 2018 Dec 6;9:728. https://doi.org/10.3389/ fendo.2018.00728

22. Liu M-M, Liu Q-J, Wen J, Wang M, Wu L-Y, Qu M-L, et al. Waist-to-hip ratio is the most relevant obesity index at each phase of insulin secretion among obese patients.J Diabetes Complications. 2018 Jul;32(7):670-6. https://doi.org/10.1016/j.jdiacomp.2018.04.006

23. González DA, Nazmi A, Yudkin JS, Victora CG. Life-course socioeconomic factors, skin colour and abdominal obesity in adulthood in a Brazilian birth cohort. Public Health Nutr. 2009 Nov;12(11):2225-35. https://doi.org/10.1017/S1368980009990607

24. Jennum P, Ibsen R, Knudsen S, Kjellberg J. Comorbidity and mortality of narcolepsy: a controlled retro- and prospective national study. Sleep. 2013 Jun 1;36(6):835-40. https://doi.org/10.5665/sleep.2706

25. Cohen A, Mandrekar J, St Louis EK, Silber MH, Kotagal S. Comorbidities in a community sample of narcolepsy. Sleep Med. 2018 Mar;43:14-8. https://doi.org/10.1016/j.sleep.2017.11.1125

26. Inocente CO, Lavault S, Lecendreux M, Dauvilliers Y, Reimao R, Gustin M-P, et al. Impact of obesity in children with narcolepsy. CNS Neurosci Ther. 2013 Jul;19(7):521-8. https://doi.org/10.1111/ cns.12105 
27. Wang Z, Wu H, Stone WS, Zhuang J, Qiu L, Xu X, et al. Body weight and basal metabolic rate in childhood narcolepsy: a longitudinal study. Sleep Med. 2016 Sep;25:139-44. https://doi.org/10.1016/j. sleep.2016.06.019

28. Fronczek R, Lammers GJ, Balesar R, Unmehopa UA, Swaab DF. The number of hypothalamic hypocretin (orexin) neurons is not affected in Prader-Willi syndrome. J Clin Endocrinol Metab. 2005 Sep;90(9):5466-70. https://doi.org/10.1210/jc.2005-0296

29. van Holst RJ, van der Cruijsen L, van Mierlo P, Lammers GJ, Cools R, Overeem S, et al. Aberrant food Choices after Satiation in Human Orexin-Deficient Narcolepsy Type 1. Sleep. 2016 Nov 1;39(11):1951-9. https://doi.org/10.5665/sleep.6222

30. Serretti A, Mandelli L. Antidepressants and body weight: a comprehensive review and meta-analysis. J Clin Psychiatry. 2010 Oct;71(10):1259-72. https://doi.org/10.4088/JCP.09r05346blu

31. Instituto Brasileiro de Geografia e Estatística [Internet]. Pesquisa nacional por amostra de domicílios. Brasília: IBGE; 2015.

Available from: https://www.ibge.gov.br/estatisticas/sociais/ educacao/9127-pesquisa-nacional-por-amostra-de-domicilios. html?=\&t=resultados

32. Jennum P, Knudsen S, Kjellberg J. The economic consequences of narcolepsy. J Clin Sleep Med. 2009 Jun 15;5(3):240-5.

33. Bayard S, Croisier ML, Cochen De Cock V, Scholz S, Dauvilliers Y. Executive control of attention in narcolepsy. PloS One. $2012 \mathrm{Apr}$ 25;7(4):e33525. https://doi.org/10.1371/journal.pone.0033525

34. Inocente CO, Lavault S, Lecendreux M, Dauvilliers Y, Reimao R, Gustin M-P, et al. Impact of obesity in children with Narcolepsy. CNS Neurosci Ther. 2013 Jul;19(7):521-8. https://doi.org/10.1111/ cns.12105

35. Hagman E, Danielsson P, Brandt L, Svensson V, Ekbom A, Marcus C. Childhood obesity, obesity treatment outcome, and achieved education: a prospective cohort study. J Adolesc Health. 2017 Oct;61(4):508-13. https://doi.org/10.1016/j.jadohealth.2017.04.009

36. Fornazieri MA, Doty RL, Bezerra TFP, Pinna F de B, Costa FO, Voegels $\mathrm{RL}$, et al. Relationship of socioeconomic status to olfactory function. Physiol Behav. 2019 Jan 1;198:84-9. https://doi.org/10.1016/j. physbeh.2018.10.011

37. Plazzi G, Moghadam KK, Maggi LS, Donadio V, Vetrugno R, Liguori R, et al. Autonomic disturbances in narcolepsy. Sleep Med Rev. 2011 Jun;15(3):187-96. https://doi.org/10.1016/j.smrv.2010.05.002

38. Klein G, Burghaus L, Vaillant M, Pieri V, Fink GR, Diederich N Dysautonomia in narcolepsy: evidence by questionnaire assessment. J Clin Neurol. 2014 Oct 6;10(4):314-9. https://doi.org/10.3988/ jcn.2014.10.4.314

39. Peyron C, Tighe DK, van den Pol AN, de Lecea L, Heller HC, Sutcliffe $J G$, et al. Neurons containing hypocretin (orexin) project to multiple neuronal systems.J Neurosci. 1998 Dec 1;18(23):9996-10015. https:// doi.org/10.1523/JNEUROSCI.18-23-09996.1998

40. Huang Y-S, Hsiao I-T, Liu F-Y, Hwang F-M, Lin K-L, Huang W-C, et al. Neurocognition, sleep, and PET findings in type 2 vs type 1 narcolepsy. Neurology. 2018 Apr 24;90(17):e1478-87. https://doi. org/10.1212/WNL.0000000000005346

41. Szakacs Z, Dauvilliers Y, Mikhaylov V, Poverennova I, Krylov S, Jankovic S, et al. Safety and efficacy of pitolisant on cataplexy in patients with narcolepsy: a randomised, double-blind, placebocontrolled trial. Lancet Neurol. 2017 Mar;16(3):200-7. https://doi. org/10.1016/S1474-4422(16)30333-7

42. Smith S, Rossdale J, Serry Y, Sekaran A, Drakatos P, Steier J. Multiple dimensions of excessive daytime sleepiness. J Thorac Dis. 2018 Jan;10 Suppl 1:S170-6. https://doi.org/10.21037/jtd.2017.11.32

43. Fong SY, Ho CK, Wing YK. Comparing MSLT and ESS in the measurement of excessive daytime sleepiness in obstructive sleep apnoea syndrome. J Psychosom Res. 2005 Jan;58(1):55-60. https:// doi.org/10.1016/j.jpsychores.2004.05.004

44. Vignatelli L, Plazzi G, Barbato A, Ferini-Strambi L, Manni R, Pompei F, et al. Italian version of the Epworth sleepiness scale: external validity. Neurol Sci. 2003 Feb;23(6):295-300. https://doi.org/10.1007/ s100720300004

45. Marra L, Carratu P, Dragonieri S, Quaranta VN, Castellana G, Resta O. The role of education in the self-compilation of Epworth sleepiness scale questionnaire in patients with suspected obstructive sleep apnea. Sleep Breath. 2018 May;22(2):485-6. https://doi.org/10.1007/ s11325-017-1586-2

46. Gander PH, Marshall NS, Harris R, Reid P. The Epworth Sleepiness scale: influence of age, ethnicity, and socioeconomic deprivation. Epworth Sleepiness scores of adults in New Zealand. Sleep. 2005 Feb;28(2):249-54. https://doi.org/10.1093/sleep/28.2.249 